\title{
Observational study of a case of fibromyalgia treated with Ozone Therapy: local and systemic effects documented with Metatron Hunter
}

\author{
Bruno Fioravanti \\ Oxygen Ozone Therapy Scientific Society, Gorle (BG), Italy
}

\begin{abstract}
This work has examined the use of Metatron diagnostics on fibromyalgia, analyzing the evolution and the effectiveness of treatment with oxygen-ozone therapy.
\end{abstract}

\section{Metatron}

The diagnostic equipment is based on spectral analysis of electromagnetic fields swirling pattern of biological subjects.

Experiments conducted at the Moscow Institute of Applied Psychophysics have confirmed the close relationship between trends swirling electromagnetic fields and biological systems: those fields are used as means of extra and intracellular interaction and they have an important role in information transfer and in the interaction between different biological systems. ${ }^{1,2}$

Biological systems recognize and isolate the necessary information from the background noise in which extra and intracellular communications take place. Research conducted by the Institute about the energetic fields on plants and animals concluded that a whirling magnetic field extremely weak and low frequency around all the biological systems exist.

Unlike magnetic resonance imaging and computed tomography, nonlinear analysis (NLS) does not require high-intensity electromag-

Correspondence: Bruno Fioravanti, Oxygen Ozone Therapy Scientific Society, Via Roma 69, 24020 Gorle (BG), Italy.

E-mail: fiorbrunodoc54@gmail.com

Key words: Fibromyalgia; Oxygen-0zone; Metatron.

Conflict of interest: the author declares no potential conflict of interest.

Received for publication: 23 June 2016.

Accepted for publication: 25 July 2016.

CCopyright B. Fioravanti, 2016

Licensee PAGEPress, Italy

Ozone Therapy 2016; 1:6272

doi:10.4081/ozone.2016.6272

This article is distributed under the terms of the Creative Commons Attribution Noncommercial License (by-nc 4.0) which permits any noncommercial use, distribution, and reproduction in any medium, provided the original author(s) and source are credited. netic fields or contrast chemical means. In Figure 1 the findings of various diagnostic methods compared with the NLS analysis are presented. As functionality scale quality you use the icons listed in Figure 2.

\section{Case Report}

A 50-year-old female, married, with two daughters, sedentary work activity, regular physical activity. Diagnosis of fibromyalgia at age of 48 , hyperhomocysteinemia not being treated; at age of 24 removal of the right scalene muscle for the thoracic outlet syndrome. Ultrasonography of the inferior limb: chronic failure of the inferior limbs at principal localization under knee.

Subjective symptoms at the beginning of the therapeutic relationship: dizziness, cervicobrachialgia, fatigue, diffuse arthralgia, anxiety, tachycardia, thermoregulation disorders, chest tightness.

\section{Performed therapy}

As per protocol, the patient was subjected to 10 sessions of 0xygenOzone $\left(\mathrm{O}_{2}-\mathrm{O}_{3}\right)$, from March 2 to April 24 2016, through subcutaneous injections of $\mathrm{O}_{2}-\mathrm{O}_{3}$ mixture in the legs, buttocks, vertebral column, abdomen, in the residual scar from cesarean delivery, and in the shoulder joint, of cervical and lumbar spine.

The zones were chosen on the basis of the lower limb circulatory problems of the patient, and of the painful zones. Because of organization problems of the patient, weekly sessions were administered. At the beginning, during and the end of the cycle scans with Metatron system were performed.

The patient was treated before with Neuropsychophisic Optimization sessions and tissue activation (for more info, irf.it) and she is following a Clinical Nutritional therapy, under the guide of the analysis of the Corporeal Composition of the Neurovegetative System (for info, Biotekna.com). She also followed a therapy based on medical mushrooms.

In Table 1 the variation of the measured parameters is showed.

In Figures 3-5 the comparation between the initial measuring (on the left) and the final measuring (on the right) of the ozone therapy cycle; is showed in the box on the right the compensation changes is cited.

\section{Discussion and Conclusions}

As expected, the patient obtains important results regarding the reduction of the pain in all locations; the feelings of looseness and strength increase; there is an important improvement also at the vascularization 
A)

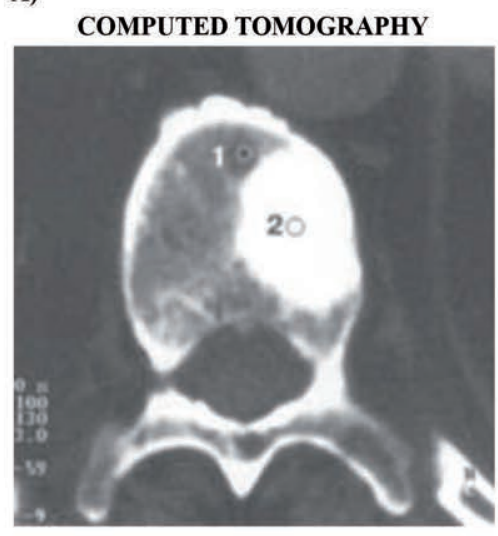

B)
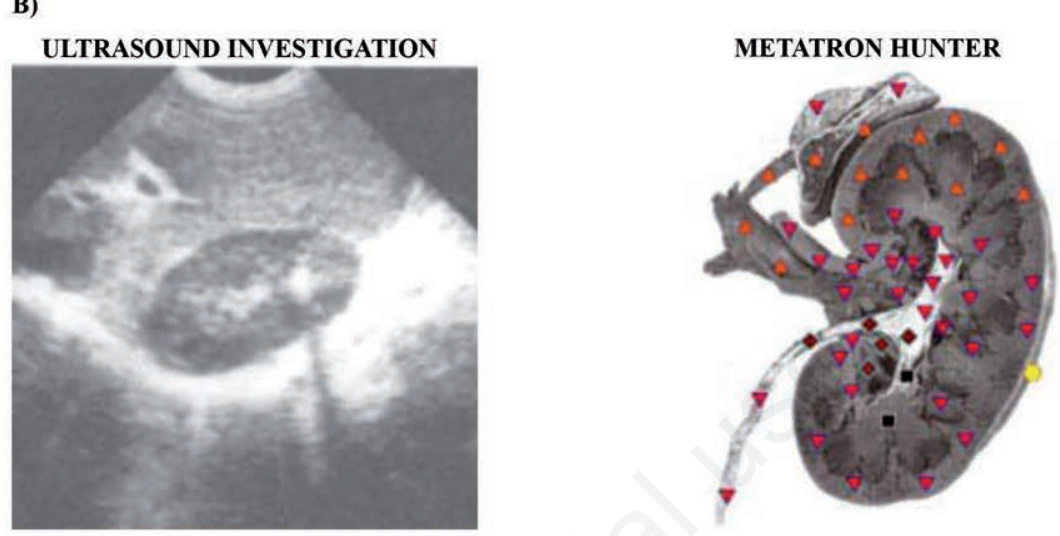

C)
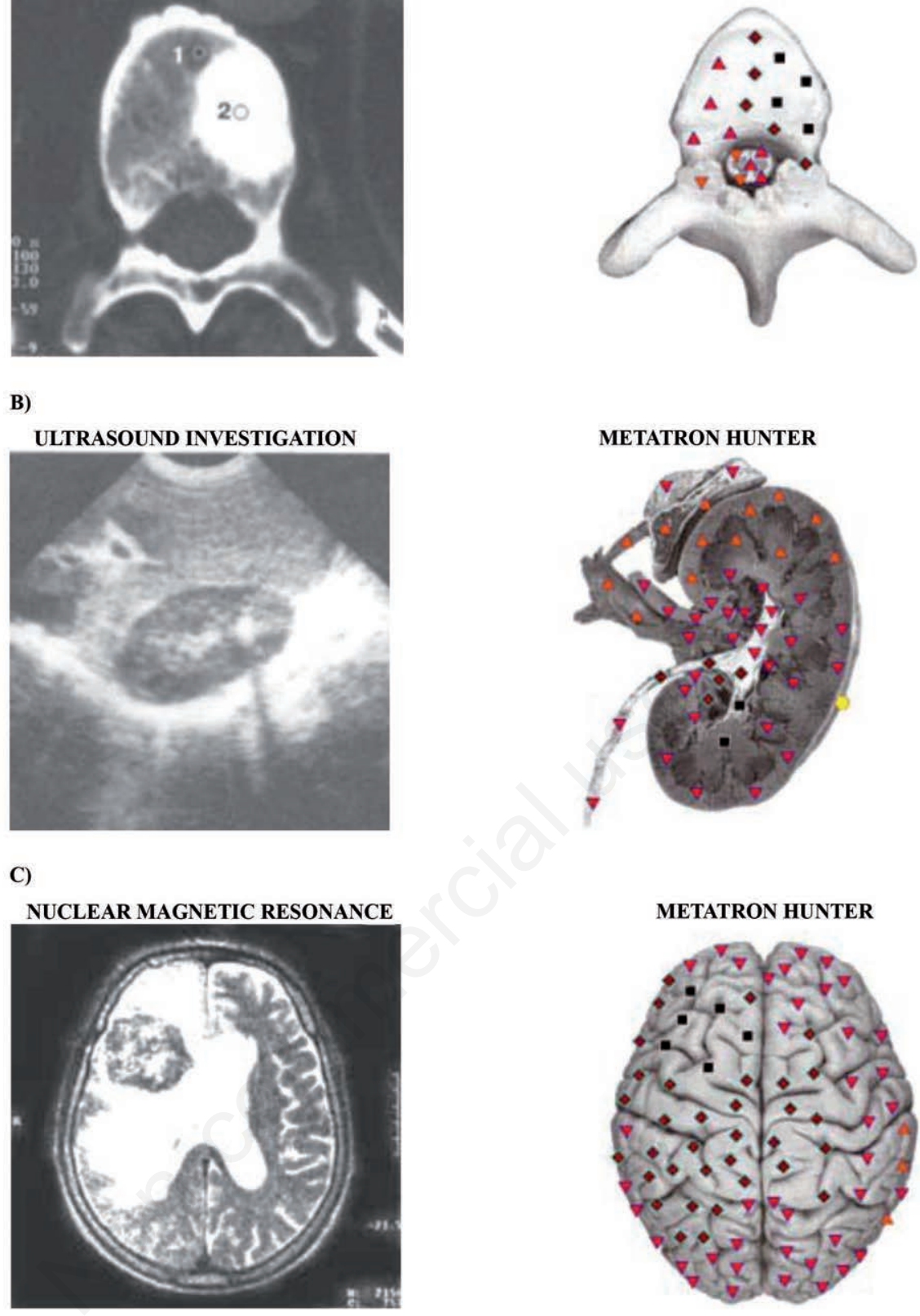

METATRON HUNTER

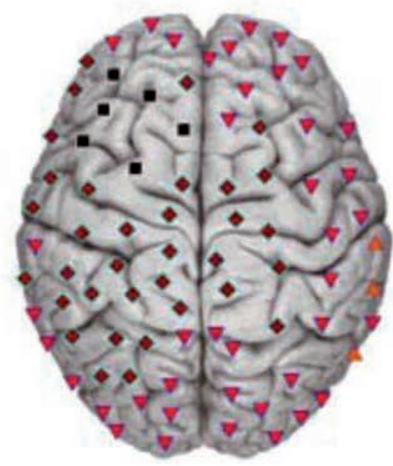

Figure 1. A) A 68 yeras old patient. Osteoblastic carcinom metastasis of prostate in the vertebral column; B) a 56 years old patient. Longitudinal section: right kidney stone; C) a 56 years old patient. Lung tumor metastasis in the the left frontal brain.

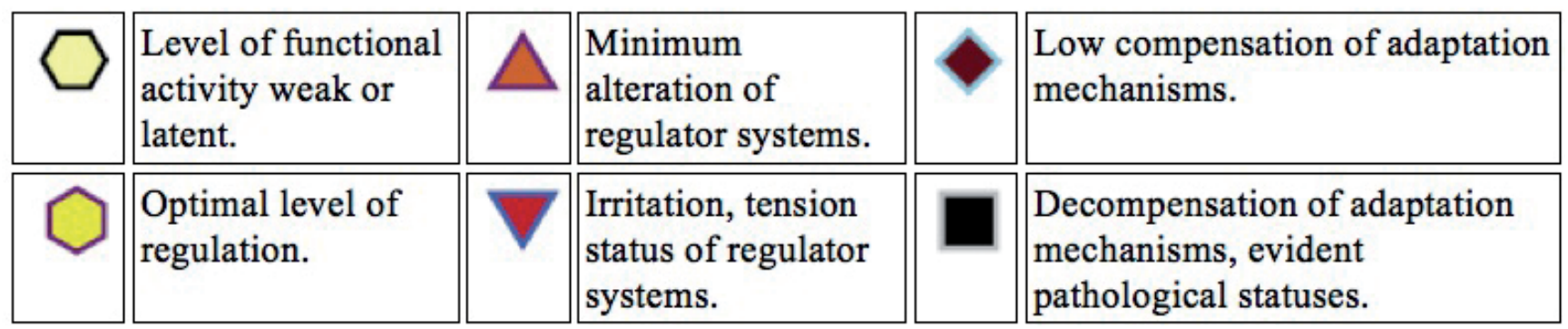

Figure 2. Icons used as functionality scale quality. 
of the inferior limb level, with an average improvement of the measured values of 25.6 on the right and 17.3 on the left, that follow the subjective feelings.

Checking other districts too, it is evident that the cranio-cervical and myocardial circulation shows significant improvements, especially at the level of the arterial blood component.

Since by common accord the intramuscular and intravascular admin- istration were avoided, and the patient refused the intrarectal administration, the results obtained at the brain and myocardium level are clearly attributable to the diffusion of gases in the entire organism due to simple subcutaneous administration. It is therefore necessary to accumulate further data to confirm this hypothesis, which could justify the clinical evidence of improvements in the systemic circulation while using only local routes of administration.

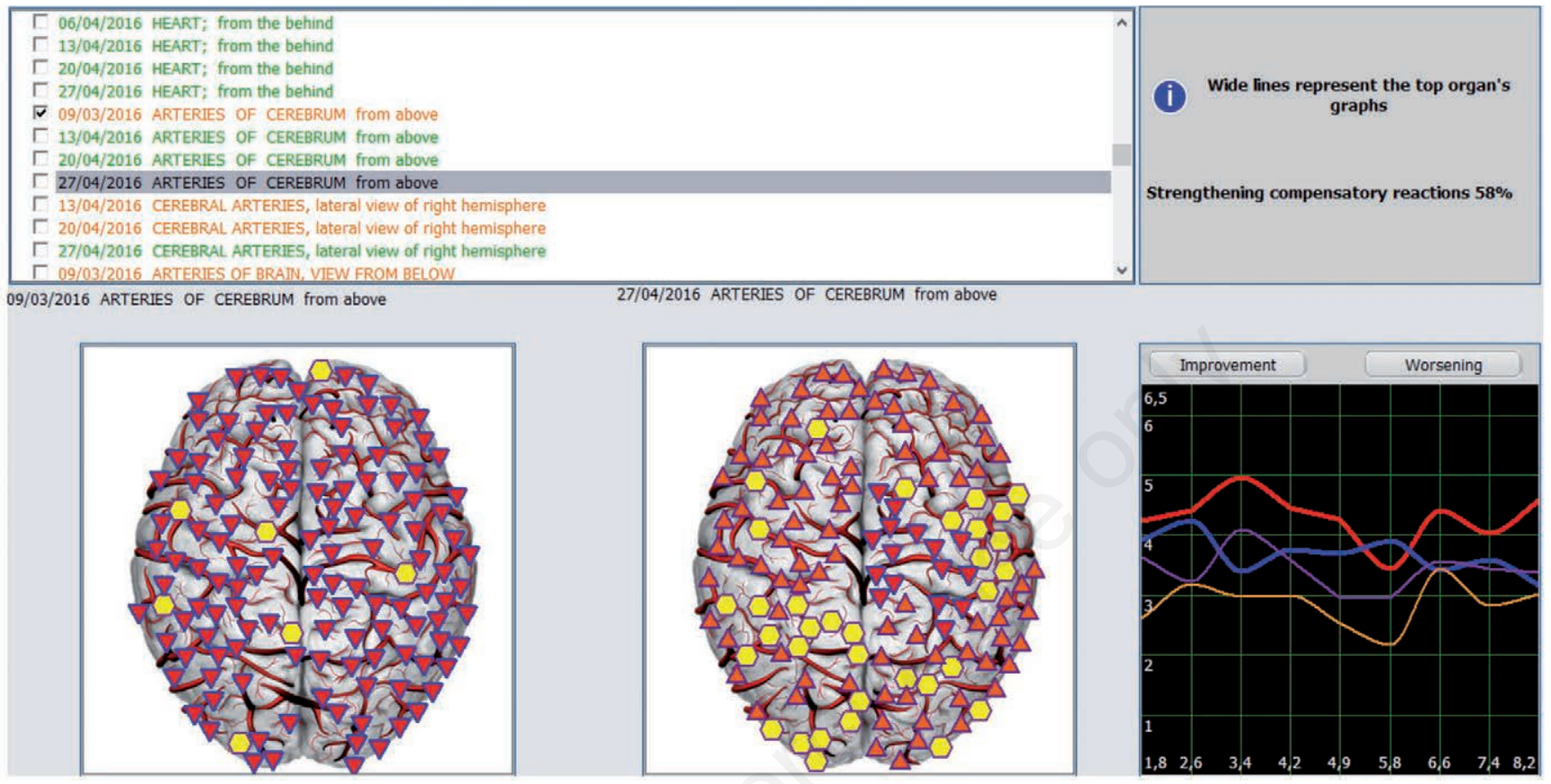

Figure 3.

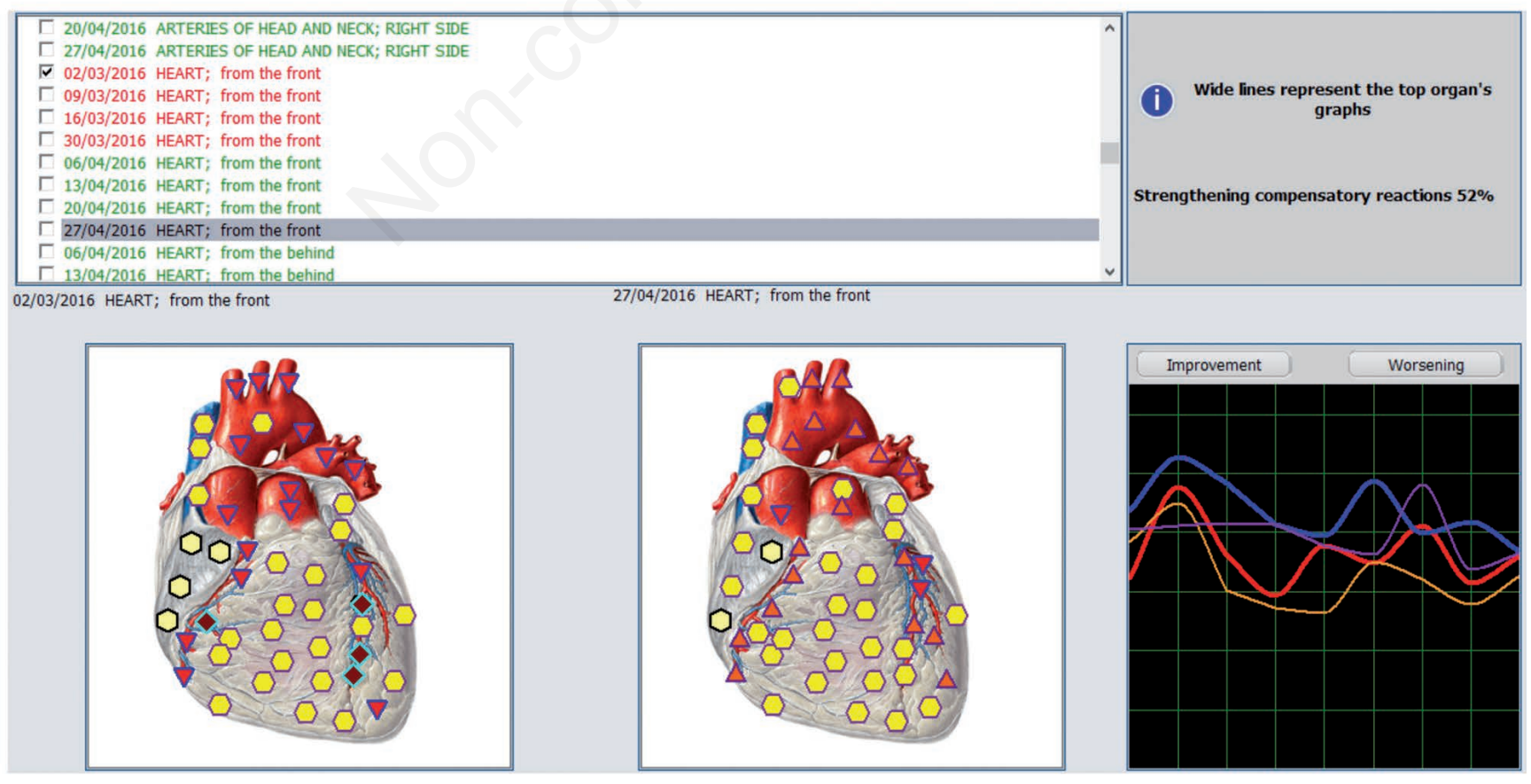

Figure 4. 


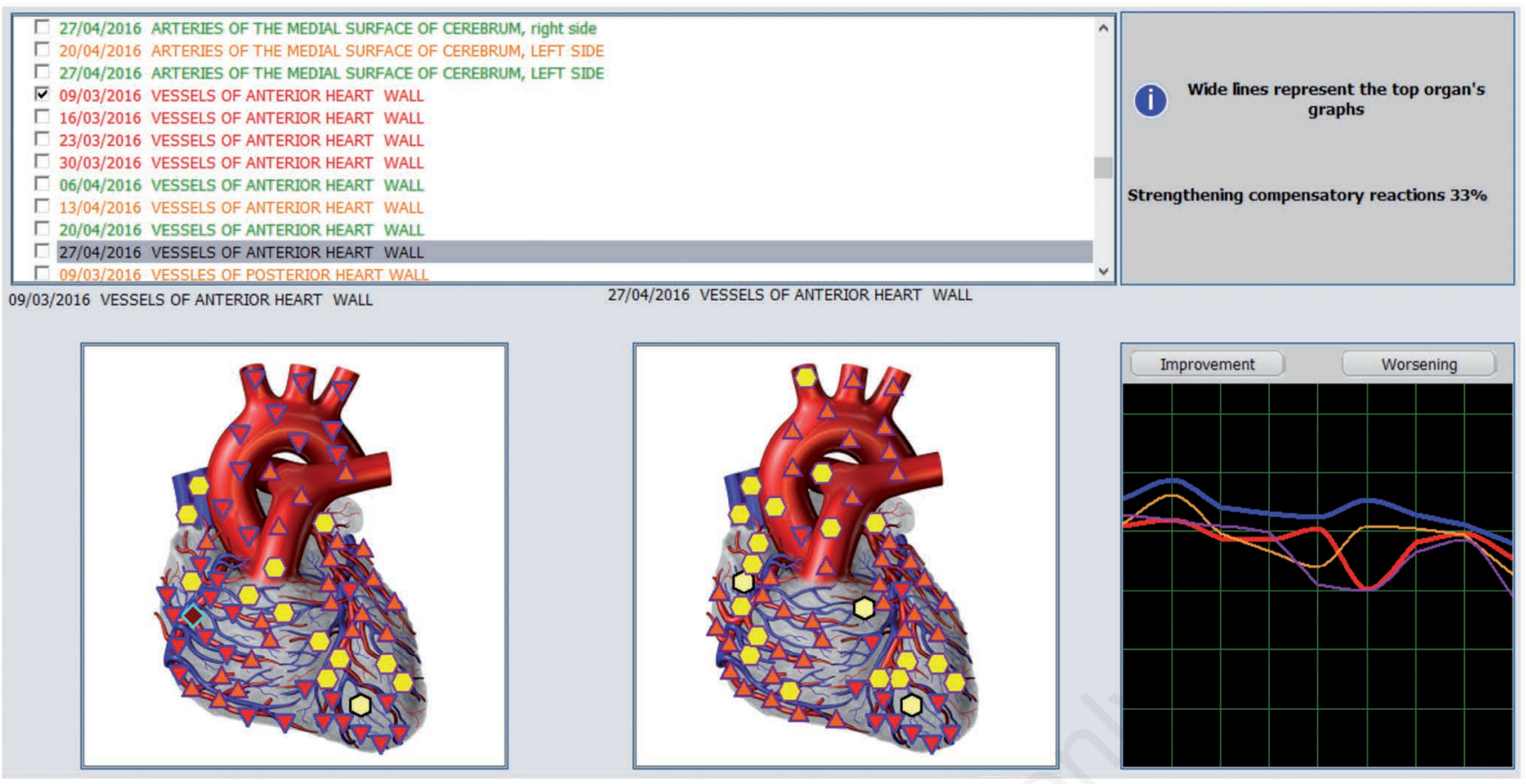

Figure 5.

Table 1. Variations of the measured parameters (compensative reinforce variations).

\begin{tabular}{lc}
\hline Pancreas & $+41 \%$ \\
Stomach & $+10 \%$ \\
\hline Intestine & $=$ \\
Kidney circulation & $+5 \%$ \\
\hline Deep thoracoabdominal circulation & $+24 \%$ \\
Heart - frontal view & $+52 \%$ \\
\hline Heart - posterior view & $=$ \\
Heart - anterior wall & $+33 \%$ \\
\hline Heart - posterior wall & $+33 \%$ \\
Left carotid artery branches & $+28 \%$ \\
\hline Right carotid artery branches & $+27 \%$ \\
Cerebral arteries-cranial view & $+58 \%$ \\
\hline Cerebral arteries-caudal view & $+52 \%$ \\
Venous skull circle/cervical left & $+5 \%$ \\
\hline Venous skull circle /cervical right & $+6 \%$ \\
Right brachial vessels & $+3 \%$ \\
\hline Left brachial vessels & $+6 \%$ \\
Right thigh circulation & $+15 \%$ \\
\hline Left thigh circulation & $+30 \%$ \\
Right leg arteries & $+24 \%$ \\
\hline Left leg arteries & $+12 \%$ \\
Right leg veins & $+38 \%$ \\
\hline Left leg veins & $+10 \%$ \\
Thyroid, in total & $+9 \%$ \\
\hline Reduction of irritative outbreak & $-67 \%$ \\
\hline &
\end{tabular}

\section{References}

1. K. Kirose, A. Nishiyama. NLS in diagnostics of vertebrobasilar system strokes. Actual Aspects On NLS Diagnostics. 2015;7:7-11.

2. Blaise Magnenat. NLS and tran surfing: toward quantum psychology. Actual Aspects on NLS Diagnostics. 2015;7:32-5. 